\title{
Pengukuran Panjang-Berat Ikan dan Sayuran secara Otomatis pada Budikdamber (Budi Daya Ikan dalam Ember) Menggunakan Visi Komputer dan Regresi Linier
}

\author{
Hurriyatul Fitriyah \\ Prodi Teknik Komputer, Jurusan Teknik Informatika, Fakultas Ilmu Komputer, Universitas Brawijaya, \\ Jalan veteran 8 Malang, Indonesia \\ hfitriyah@ub.ac.id
}

Diterima : 28 Aguustus 2020

Disetujui : 28 September 2020

\begin{abstract}
Abstrak-Budi daya ikan dalam ember atau Budikdamber kini banyak diminati masyarakat Indonesia karena dapat dilakukan pada lahan yang terbatas. Lele dan kangkung adalah ikan dan sayuran yang sering dikembangbiakkan pada budikdamber ini. Meski keduanya tergolong mudah untuk tumbuh, namun pemantauan kondisi masih perlu dilakukan. Diantaranya adalah ukuran ikan dan sayuran yang dapat menunjukkan apakah kondisi keduanya baik atau memerlukan penanganan. Penelitian ini membuat sistem pengukuran berat dan panjang ikan dan sayuran pada budikdamber menggunakan visi komputer untuk mengambil fitur dan regresi linier untuk memprediksi ukuran. Kamera dipilih sebagai sensor agar pengukuran dapat dilakukan secara non-kontak. Fitur yang digunakan adalah luas area dari lele dan kangkung yang diperoleh berdasarkan proses segmentasi pada ruang warna Hue dan Saturation. Prediksi berat dan panjang menggunakan Regresi Linier dengan input luas area dan output berat-panjang melalui proses pelatihan data. Hasil pengujian menggunakan Kfold cross Validation pada gambar uji menunjukkan nilai koefisien determinasi $\mathbf{R}^{\mathbf{2}}$ yang tinggi pada panjang $\&$ berat lele $(0,92 \& 0,88)$, namun rendah pada panjang $\&$ berat kangkung (0,43 \& 0,07). Meski demikian, Mean Absolute Percentage Error (MAPE) dari prediksi ukuran kangkung masih baik yakni $13,37 \%$ untuk berat dan $5,78 \%$ untuk panjang. MAPE dari pengukuran panjang lele adalah 1,49\% dan berat lele adalah 4,49\%. Nilai-nilai tersebut menunjukkan bahwa algoritma yang dibangun sudah memiliki akurasi yang baik, namun masih perlu perbaikan dalam hal prediksi ukuran kangkung.
\end{abstract}

Kata Kunci-budikdamber, hue, regresi linier, saturation, visi komputer

\section{PENDAHULUAN}

Ketahanan pangan merupakan kondisi dimana masyarakat tercukupi ketersediaan pangannya dan mudah mendapatkannya. Hal ini sangat penting karena ketersediaan pangan juga mempengaruhi stabilitas nasional. Salah satu unsur dalam ketahanan pangan adalah Kemandirian Pangan dimana masyarakat mampu secara mandiri memproduksi sumber pangannya (Bulog, 2014). Dua dari tiga pilar ketahanan pangan adalah ketersediaan dan keterjangkauan. Untuk itulah banyak upaya untuk menghasilkan metode penumbuhan atau pengembangbiakan produk pangan di rumah agar dapat dikonsumsi seharihari oleh masyarakat. Banyak metode-metode seperti hidroponik dan akuaponik yang dapat mengatasi keterbatasan lahan yang juga menjadi permasalahan di Indonesia.

Salah satu metode yang kini ramai diberdayakan adalah budikdamber atau Budi Daya Ikan dalam Ember. Metode ini hampir sama dengan akuaponik yang menggunakan media air 
untuk menghasilkan ikan dan sayuran dengan lahan terbatas. Namun Budikdamber ini lebih ringkas lagi karena hanya menggunakan media ember dengan ukuran relatif kecil yakni 60 liter. Pembuat metode ini adalah Juli Nursandi yang menyebutkan bahwa pemeliharaan selama 42 hari mampu menghasilkan ikan lele seberat 2.440 gram dan 42 ikat kangkung (Nursandi, 2018). Hasil ini sangat menarik terlebih dapat dilakukan dalam skala rumah tangga dan media ember.

Meski terbilang cukup sederhana, ikan dan sayuran yang dibudidayakan juga perlu pemantauan dan perawatan. Pertumbuhan panjang ikan rata-rata selama 42 hari adalah $\pm 7 \mathrm{~cm}$ dan pertumbuhan bobot ikan rata-rata adalah 18,45 gram untuk ukuran tebar 5-12 cm dan 47,74 gram untuk ukuran tebar 12-14 cm (Nursandi, 2018). Pengukuran berat-panjang juga dibutuhkan untuk menentukan waktu panen.

Pemantauan dapat dilakukan secara manual dengan visual. Namun keberadaan IoT (Internet of Things) memungkinakn untuk dilakukannya pemantauan dari jarak jauh menggunakan jaringan internet. Penelitian ini memungkinkan monitoring ukuran panjang-berat dari ikan dan sayuran sebagai bagian dari IoT dengan visi komputer. Metode pada visi komputer yang digabungkan dengan algoritma machine learning memungkinkan pengukuran secara non-kontak dan otomatis. Pengukuran berat tidak perlu menggunakan sensor berat dan pengukuran panjang tidak perlu menggunakan penggaris atau sensor jarak.

Pengukuran panjang dan berat objek menggunakan visi komputer dan machine learning di bidang pertanian telah dilakukan oleh beberapa peneliti. Penelitian oleh (Hartono, Sasono, Anggraeni, Suwanda, \& P, 2019) menggunakan luas bounding-box yang diperoleh dari deteksi tepian citra ikan koi menggunakan canny-edge detection. Panjang ikan didapatkan dari konversi panjang pixel $\mathrm{ke} \mathrm{cm}$ sedangkan berat ikan didapatkan dari konversi pixel ke gram. Penelitian lain oleh (Islamadina, Pramita, Arnia, Munadi, \& Iqbal, 2018) juga menggunakan konversi pixel $\mathrm{ke} \mathrm{cm}$ dan pixel ke gram untuk mendapatkan panjang, tinggi dan berat dari ikan dalam kolam. Nilai pixel didapatkan dengan melakukan segmentasi citra ikan menggunakan region growing. Penelitian lain oleh (SanchezTorres, Ceballos-Arroyo, \& Robles-Serano, 2018) menemukan garis-tengah ikan yang ditentukan menggunakan regresi linier atau regresi polinomial orde 3 dan 4 dari koordinat tepian ikan. Panjang ikan diprediksi menggunakan regresi linier, KNN dan support-verctor regression (SVR). Berat ikan didapatkan dari regresi linier, KNN dan support-verctor regression dari panjang ikan hasil prediksi. Ketiga penelitian tersebut menunjukkan bahwa informasi pixel dari objek yang terdeteksi dapat digunakan untuk mengukur berat dan panjang melalui metode konversi atau regresi. Metode regresi linier juga digunakan untuk memprediksi panjang dan berat tanaman yakni pengukuran pada buah manggis (Suhandy \& Ahmad, 2003) dan buah blimbing (Fitriyah, Setiawan, \& Masruri, 2020). Keduanya menggunakan thresholding untuk mendapatkan fitur jumlah pixel dari buah.

Penelitian-penelitian tersebut menunjukkan bahwa informasi pixel pada citra objek dapat digunakan untuk memprediksi ukuran (panjang, tinggi, berat) menggunakan metode machine learning (regresi, KNN, SVR, dll). Sehingga penelitian ini menerapkan metode visi komputer dan machine learning tersebut untuk dapat mengukur berat-panjang ikan dan sayur pada sistem budidaya budikdamber. Ikan yang digunakan adalah lele sedangkan sayur yang digunakan adalah kangkung. Kedua nya merupakan ikan dan tanaman yang disarankan dalam budikdamber.

\section{METODE}

Secara umum sistem yang dibangun menggunakan input citra ember budikdamber yang ditangkap menggunakan kamera. Citra tersebut kemudian diolah untuk mendapatkan pixel lele dan kangkung sebagai fitur. Nilai pixel tersebut kemudian dijadikan input untuk memprediksi panjang-berat lele dan kangkung menggunakan metode regresi linier. Akurasi dari prediksi panjang-berat menggunakan koefisien determinan $\mathrm{R}^{2}$ dan MAPE (Mean Absolute Percentage Error). 


\section{A. Pengambilan Gambar}

Gambar ember dalam budikdamber ini diambil dari posisi kamera yang tegak lurus menghadap ke bawah. Kamera juga diletakkan tepat di tengah ember. Posisi tersebut bertujuan untuk dapat memotret lele dan kangkung secara bersamaan hanya dalam satu frame. Kamera ditempatkan setinggi $50 \mathrm{~cm}$ di atas ember dan digantungkan secara fix kepada sebuah tiang yang dimodifikasi. Pengaturan tinggi dan posisi hadap yang fix tersebut untuk menjamin rasio pixel $\mathrm{ke} \mathrm{cm}$ yang sangat penting dalam prediksi panjang dan juga berat. Kamera yang digunakan adalah webcam standar yang mengambil gambar dengan ukuran tetap yakni 240x320 pixel.

Pengambilan gambar dilakukan dengan kondisi cahaya yang cukup guna memudahkan proses deteksi lele dan kangkung. Setting alat untuk pengambilan gambar dapat dilihat di Gambar 1. Warna ember juga dipilih warna merah agar memudahkan proses segmentasi kangkung yang berwarna hijau. Kondisi air juga jernih agar lele mudah terlihat. Terdapat lampu yang dapat dinyalakan jika pengambilan dilakukan di dalam ruangan. Namun dalam penelitian ini, pengambilan gambar dilakukan di luar ruangan dengan cahaya matahari yang terang sehingga tidak membutuhkan cahaya tambahan.

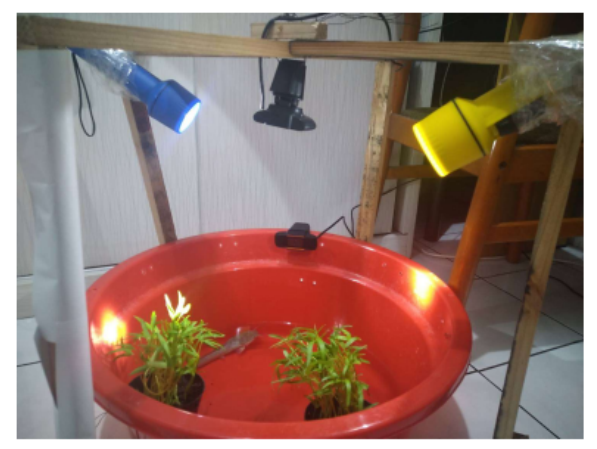

Gambar 1. Pengambilan gambar ember budikdamber

Sebagai simulasi, ember hanya diisi oleh 2 kangkung yang diletakkan terpisah. Ember juga hanya diisi oleh 2 lele dengan ukuran besar dan kecil. Hanya gambar dengan posisi lele yang terpisah yang akan dievaluasi. Hal tersebut bertujuan untuk memudahkan proses pendeteksian objek. Ukuran lele yang berbeda, besar dan kecil, digunakan untuk mengetahui berapa besar minimum lele yang dapat dideteksi.

Contoh hasil tangkapan gambar yang digunakan dalam penelitian ini diperlihatkan pada Gambar 2. Sebanyak 12 gambar ember dikumpulkan untuk perancangan dan pengujian dari metode yang dibangun.

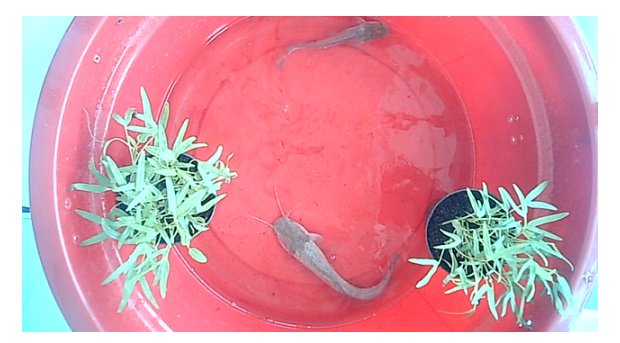

Gambar 2. Contoh gambar ember budikdamber

\section{B. Visi Komputer}

Proses visi komputer bertujuan untuk mendapatkan fitur dari citra input. Visi komputer menggunakan beragam teknik dalam pengolahan citra digital seperti konversi warna, segmentasi, dan filtering. Dalam penelitian ini, terdapat 4 tahapan pengolahan citra digital yang dilakukan, yakni (1) Konversi warna RGB ke Hue dan Saturation, (2) Segmentasi objek menggunakan metode thresholding, (3) (4) cropping area untuk pendeteksian kangkung dan lele, dan (4) Pengubahan foreground menjadi background jika jumlah connected-component sebuah blob terdeteksi adalah kecil. Tujuan akhir dari penerapan visi komputer ini adalah mendapatkan jumlah pixel dari masing-masing kangkung dan lele.

B.1. Konversi Warna dari RGB ke Hue dan Saturation

Kangkung merupakan tanaman dengan warna daun yang khas yakni hijau. Warna hijau tersebut akan lebih mudah dideteksi menggunakan Hue daripada RGB. Berbeda dengan RGB, nilai Hue sebuah objek secara umum tidak terpengaruh oleh pencahayaan yang berbeda. Konsep Hue yang merupakan color-wheel dengan sudut $360^{\circ}$ akan memudahkan proses segmentasi dimana sebuah warna memiliki nilai derajat yang spesifik. Konversi warna dari RGB ke Hue menggunakan 
Persamaan 1.R adalah nilah komponen Red, G adalah Green dan B adalah Blue.

$$
\text { Hue }=\left\{\begin{array}{c}
0^{\circ}, \Delta=0 \\
60^{\circ} \times\left(\frac{G-B}{\Delta} \bmod 6\right), C_{\max }=R \\
60^{\circ} \times\left(\frac{B-R}{\Delta}+2\right), C_{\max }=G \\
60^{\circ} \times\left(\frac{R-G}{\Delta}+4\right), C_{\max }=B
\end{array}\right.
$$

dimana,

$$
\begin{gathered}
C_{\max }=\max (R, G, B) \\
C_{\text {min }}=\min (R, G, B) \\
\Delta=C_{\text {max }}-C_{\text {min }}
\end{gathered}
$$

Lele merupakan ikan yang memiliki ciri khas berwarna hitam dan abu-abu. Kedua warna ini mudah dideteksi pada warna Saturation dengan nilai yang sangat rendah. Saturation bernilai 0-255 dimana nilai tinggi menujukkan warna yang murni dan nilai rendah menujukkan nilai yang memudar dan cenderung hitam keabu-abuan. Value dan Grayscale tidak dipilih untuk deteksi lele karena bagian tubuh lele berwarna abu-abu memiliki nilai kecerahan yang tinggi dan menyerupai objek kangkung, ember dan air. Konversi warna dari RGB ke Saturation menggunakan Persamaan 2.

$$
S=\left\{\begin{array}{c}
0, \text { jika } C_{\max }=0 \\
\frac{\Delta}{C_{\max }}, \text { jika } C_{\max } \neq 0
\end{array}\right.
$$

\section{B.2. Segmentasi Objek menggunakan Thresholding}

Metode Thresholding dipilih karena lebih mudah mendeteksi area (region) kangkung dan lele dari pada tepiannya. Metode ini juga sederhana karena hanya menggunakan nilai batas (threshold) dari intensitas warna. Nilai batas Hue untuk mendeteksi warna hijau pada kangkung adalah $108-216$ pada skala 0-255 atau 0.3-0.6 pada skala 0-1). Nilai batas Saturation untuk mendeteksi lele adalah 0-127 oada skala 0-255 atau $0-0.5$ pada skala $0-1$. Nilai batas tersebut dipilih secara manual berdasarkan pengamatan. Intensitas warna dari pixel akan diubah menjadi nilai 1 jika berada pada rentang nilai batas dan 0 jika diluarnya. Hasil dari Thresholding adalah citra biner dimana objek memiliki nilai 1 dan background memiliki nilai 0 . Citra biner hasil segmentasi pada Hue dinamakan $\operatorname{Segm}_{H}$ sedangkan hasil segmentasi pada Saturation dinamakan $\mathrm{Segm}_{S}$ dan dirangkum seperti pada Persamaan (3) dan Persamaan (4).

$\operatorname{Segm}_{H}=\left\{\begin{array}{c}1, j i k a 108<\text { Hue }<216 \\ 0, \text { jika lainnya }\end{array}\right.$

$\operatorname{Segm}_{S}=\left\{\begin{array}{c}1, \quad j i k a 0<S<127 \\ 0, \text { jika lainnya }\end{array}\right.$

$\operatorname{Segm}_{H}$ tidak langsung dapat dijadikan citra hasil segmentasi kangkung sebab pot kangkung yang berwarna hitam juga terdeteksi sebagai kangkung. Hal ini tidak diinginkan sebab akan menambah area dari kangkung yang sebenarnya. Karena pot kangkung berwarna sama dengan lele, yakni hitam, maka pixel kangkung pada gambar

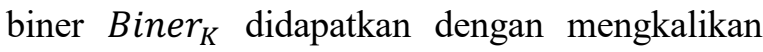
masing-masing pixel pada koordinat bersesuaian (element-wise product) pada $\operatorname{Segm}_{H}$ dengan $\neg \operatorname{Segm}_{S}$ (negasi). Segm ${ }_{S}$ juga tidak dapat langsung digunakan untuk mendeteksi piksel lele sebab beberapa warna hijau pada kangkung adalah gelap sehingga juga memiliki nilai Saturation yang rendah seperti halnya lele. Piksel lele pada citra biner Biner $_{L}$ dideteksi dengan mengkalikan masing-masing piksel pada koordinat bersesuaian (element-wise product) pada Segm $_{S}$ dengan $\neg$ Biner $_{K}$. Proses ini ditunjukkan pada Persamaan (5) dan Persamaan (6).

Biner $_{K}=\operatorname{Segm}_{H} \odot \neg \operatorname{Segm}_{S}$

Biner $_{L}=$ Segm $_{S} \odot \neg$ Biner $_{K}$

B.3. Cropping area pendeteksian kangkung dan lele

Proses segmentasi seringkali memunculkan kesalahan pendeteksian berupa background yang terdeteksi sebagai foreground. Dalam Biner $_{K}$, warna background alas ember yang juga berwarna hijau terdeteksi sebagai kangkung. Dalam Biner $_{L}$, sebagian kangkung memiliki saturasi yang sangat rendah menyerupai lele karena posisi nya yang terhalang daun kangkung lain sehingga 
mendapatkan cahaya yang sedikit. Cropping merupakan salah satu cara sederhana untuk memfokuskan pendeteksian objek menggunakan prior-knowledge berupa lokasi objek. Area kangkung merupakan hasil cropping dari Biner $_{K}$ hanya pada bagian ember. Lele hanya terlihat utuh pada bagian tengah ember, sehingga area lele merupakan hasil cropping dari Biner $_{L}$ pada bagian tersebut.

B.4. Pengubahan foreground dengan jumlah connected-component yang kecil menjadi background

Kesalahan pendeteksian dialami oleh hasil cropping pada Biner $_{L}$ dimana sebagian kangkung yang memiliki Saturation rendah juga terdeteksi sebagai lele. Proses filtering biasanya menggunakan morphology Filter seperti dilasi, erosi, opening dan closing, namun sayangnya metode-metode tersebut memiliki kekurangan yakni dapat merubah bentuk dari objek terdeteksi. Kangkung yang terdeteksi sebagai lele memiliki jumlah piksel yan sedikit. Lele yang terlalu kecil juga umumnya hanya terdeteksi separuh badan sehingga tidak bisa digunakan untuk proses selanjutnya. Untuk mengatasi kedua permasalahan tersebut, proses filtering dilakukan dengan merubah blob dengan jumlah connectedcomponent yang kecil menjadi background. Connected-component yang digunakan adalah 8neighborhood. Blob kecil dengan jumlah connected-component yang kurang dari 350 piksel akan diubah menjadi background.

Proses visi komputer yang diterapkan pada salah satu gambar (Gambar 2) dapat dilihat di Gambar 3. Gambar 3(a) adalah konversi RGB ke Hue, Gambar 3(b) adalah konversi RGB ke Saturation, Gambar 3(c) adalah $\operatorname{Segm}_{H}$, Gambar 3(d) adalah $\operatorname{Segm}_{S}$, Gambar 3(e) adalah Biner $_{K}$, Gambar 3(f) adalah Biner $_{L}$, Gambar 3(g) adalah

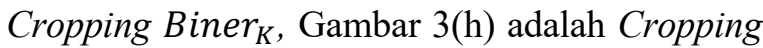
Biner $_{L}$ dan Gambar 3(i) adalah hasil filtering pada Cropping Biner $_{L}$. Output dari proses visi komputer ini adalah jumlah piksel pada masingmasing blob kangkung dan blob lele yang terdeteksi.

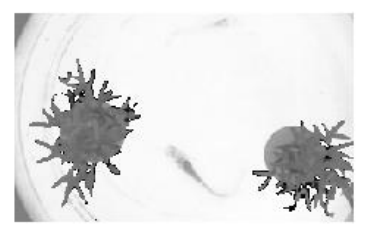

(a)

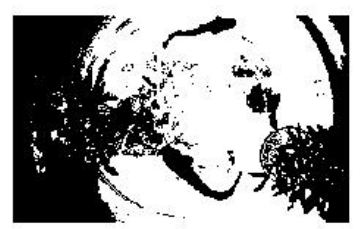

(d)

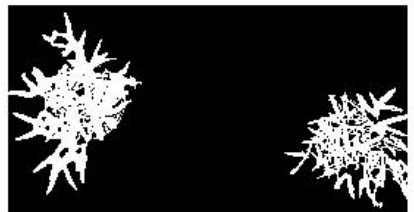

(g)

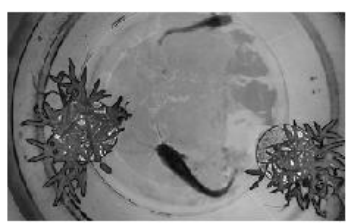

(b)

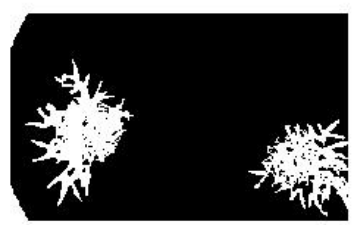

(e)

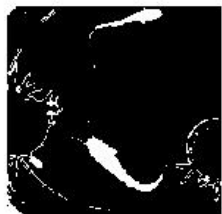

(h)

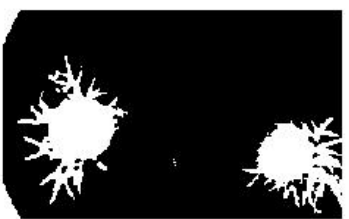

(c)

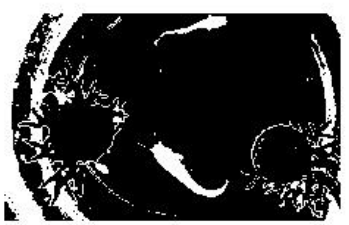

(f)

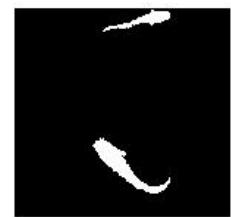

(i)

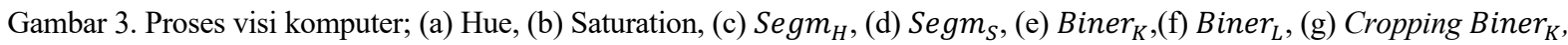
(h) Cropping Biner Cr $_{\text {, }}$ (i) hasil filtering pada Cropping Biner ${ }_{L}$ 


\section{Regresi Linier}

Jumlah piksel yang terdeteksi untuk masingmasing blob kangkung dan lele digunakan untuk memprediksi panjang dan berat dari keduanya. Panjang lele sebenarnya diukur dari ujung kepala sampai ujung ekor menggunakan penggaris dengan kondisi lele lurus. Berat lele diukur menggunakan timbangan. Panjang kangkung diukur dari permukaan tanah dalam pot sampai ujung tertinggi dari daun. Berat kangkung diukur menggunakan selisih pot berisi tanah saat ada kangkung dengan tidak.

Prediksi dilakukan menggunakan Regresi Linier $y=a x+b$. Regresi linier ini dipilih karena sederhana dan sudah menunjukkan akurasi prediksi yang tinggi pada penelitian-penelitian sebelumnya seperti yang dijelaskan pada Bab I. Nilai $a$ dan $b$ masing-masing didapatkan menggunakan Persamaan (7) dan Persamaan (8). Nilai-nilai tersebut didapat dari data latih dimana $x_{n}$ adalah jumlah piksel blob dan $y_{n}$ adalah ukuran panjang/berat sebenarnya. Ukuran berat tidak diprediksi dari panjang, namun langsung dari jumlah piksel blob. Hal ini bertujuan agar eror dari prediksi panjang tidak menambah eror dari prediksi berat.

$$
\begin{aligned}
& a=\frac{N \sum_{n=1}^{N} x_{n} y_{n}-\left(\sum_{n=1}^{N} x_{n}\right)\left(\sum_{n=1}^{N} y_{n}\right)}{N \sum_{n=1}^{N} x_{n}{ }^{2}-\left(\sum_{n=1}^{N} x_{n}\right)^{2}} \\
& b=\bar{y}-a \bar{x}=\frac{\sum_{n=1}^{N} y_{n}}{N}-m \frac{\sum_{n=1}^{N} x_{n}}{N}
\end{aligned}
$$

\section{HASIL PENGUJIAN DAN ANALISA}

Sebanyak 12 citra diambil dari kangkung dan lele dengan panjang dan berat beragam. Range panjang kangkung adalah $12-21 \mathrm{~cm}$, range berat kangkung adalah 4-26 Gram, range panjang lele adalah 11-24 cm, dan range berat lele adalah 1176 Gram.

Beberapa hasil pengambilan fitur berupa jumlah pixel menggunakan visi komputer ditunjukkan pada Gambar 4. Pendeteksian piksel kangkung menujukkan hasil yang baik. Sedangkan pendeteksian lele menunjukkan bahwa bagian ekor cenderung susah untuk dideteksi seperti pada Gambar 4(a). Hal ini disebabkan ekor lele berwarna abu-abu terang yang memiliki Saturation tinggi. Ukuran lele yang kecil juga tidak dapat terdeteksi karena hanya sebagian kecil tubuhnya berwarna gelap (saturasi rendah) seperti halnya pada Gambar 4(b). Pada ikan kecil, hanya bagian kepala yang terdeteksi sehingga kondisi tidak utuh tersebut tidak dapat dilanjutkan ke proses regresi. Dari 12 gambar yang diambil, minimum ukuran lele yang pasti dapat terdeteksi adalah panjang $15 \mathrm{~cm}$ dan berat 23 Gram. Jika ukuran lele kurang dari itu, maka pendeteksian terkadang berhasil terkadang juga tidak. Sehingga dapat dikatakan bahwa pendeteksian lele berhasil hanya pada lele dengan ukuran yang besar.
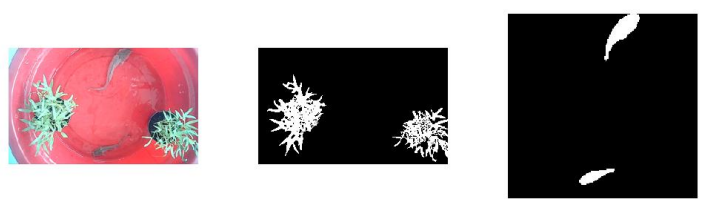

(a)
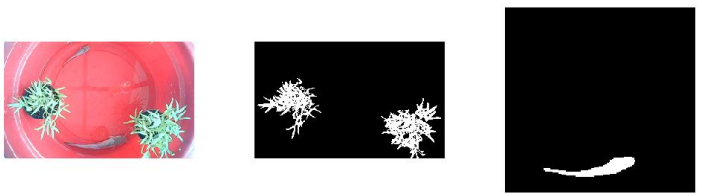

(b)

Gambar 4. Hasil proses visi komputer

Hasil pengujian dari algoritma prediksi ukuran kangkung dan lele terdapat pada Tabel 1. Koefisien determinasi $\mathrm{R}^{2}$ digunakan untuk mengetahui apakah terdapat korelasi yang baik antara jumlah piksel dari lele dan kangkung terdeteksi terhadap panjang-berat nya. Nilai $\mathrm{R}^{2}$ merupakan hasil pembagian dari Variance hasil prediksi terhadap rata-rata nilai sebenarnya, dibanding dengan Variance dari nilai sebenarnya itu sendiri. Koefisien determinasi menunjukkan seberapa bagus korelasi antara hasil prediksi terhadap nilai sebenarnya. Nilai $\mathrm{R}^{2}$ berharap $0-1$, dimana nilai 0 menunjukkkan tidak ada korelasi sama sekali dan sebaliknya nilai 1 menunjukkan ada korelasi yang sangat tinggi antara hasil prediksi dengan nilai sebenarnya.

Mean Absolute Percentage Error (MAPE) yang merupakan prosentase selisih antara ukuran asli dan ukuran hasil prediksi juga dihitung untuk menunjukkan seberapa besar kesalahan yang dihasilkan. Nilai $\mathrm{R}^{2}$ dan MAPE didapatkan 
menggunakan metode $K$-fold cross validation dimana $\mathrm{K}$ yang digunakan adalah 3 . Metode validasi yang membagi data latih dan uji secara bergantian dalam 3-fold ini diterapkan untuk mendapatkan akurasi yang lebih tepat dari semua data yang dimiliki.

Dari hasil pada Tabel 1 dapat dilihat bahwa prediksi ukuran panjang dan berat lele memiliki hasil yang baik dimana $\mathrm{R}^{2}$ panjang adalah 0.92 dan berat adalah 0.88. Nilai MAPE pada lele juga kecil yang untuk panjang adalah $1.49 \%$ dan untuk berat adalah $4.50 \%$. Nilai tersebut menunjukkan bahwa prediksi panjang dan berat lele memiliki akurasi yang tinggi.

Tabel 1. Hasil Pengujian

\begin{tabular}{|l|r|r|r|r|}
\hline \multirow{2}{*}{ Parameter } & \multicolumn{2}{|c|}{ Kangkung } & \multicolumn{2}{c|}{ Lele } \\
\cline { 2 - 5 } & Panjang & Berat & Panjang & Berat \\
\hline $\mathrm{R}^{2}(0-1)$ & 0,43 & 0,07 & 0,92 & 0,88 \\
\hline MAPE (\%) & 13,37 & 5,78 & 1,49 & 4,50 \\
\hline
\end{tabular}

Dari hasil pada Tabel 1 dapat dilihat bahwa prediksi ukuran panjang dan berat lele memiliki hasil yang baik dimana $\mathrm{R}^{2}$ panjang adalah 0.92 dan berat adalah 0.88 . Nilai MAPE pada lele juga kecil dimana untuk panjang adalah $1.49 \%$ dan untuk berat adalah $4.50 \%$. Nilai-nilai tersebut menunjukkan bahwa prediksi panjang dan berat lele memiliki akurasi yang tinggi.

Sedangkan hasil prediksi panjang dan berat kangkung menunjukkan $\mathrm{R}^{2}$ yang sangat kecil (0.43 untuk panjang dan 0.07 untuk berat). Hal ini menunjukkan bahwa hasil prediksi memiliki korelasi yang rendah dengan nilai sebenarnya. Namun demikian MAPE pada kangkung untuk panjang adalah $13.37 \%$ sedangkan untuk berat adalah $5.78 \%$. Hal ini terjadi sebab tanaman kangkung cenderung memiliki pola pertumbuhan yang beragam. Nilai tersebut juga menunjukkan bahwa prediksi tanaman kangkung perlu diperbaiki dengan mengganti atau menambah parameter lain selain jumlah pixel dari tampak atas.

\section{SIMPULAN}

Penelitan ini bertujuan membangun sebuah metode yang memprediksi ukuran panjang dan berat pada ikan dan sayuran dalam budidaya budikdamber secara otomatis menggunakan kamera. Metode yang dibangun terdiri dari visi komputer untuk ekstraksi fitur jumlah piksel dari objek pada posisi tampak atas dan regresi linier untuk memprediksi panjang dan berat objek. Hasil pengujian menunjukkan bahwa prediksi panjang dan berat lele memiliki hasil yang akurat, namun prediksi kangkung memiliki akurasi yang rendanh. Kedepannya prediksi kangkung perlu mendapatkan perbaikan baik dengan pengubahan atau penambahan fitur. Jumlah kangung dan lele dalam ember juga perlu diperbanyak agar mendapatkan simulasi prediksi yang lebih riil sesuai kondisi budikdamber sebenarnya.

\section{DAFTAR PUSTAKA}

[1] Bulog, "Pengertian Ketahanan Pangan," 2014. [Online]. Available: http://www.bulog.co.id/ ketahananpangan.php. [Accessed 268 2020].

[2] J. Nursandi, "Budidaya Ikan Dalam Ember "Budikdamber" dengan Aquaponik di Lahan Sempit," Prosiding Seminar Nasional Pengembangan Teknologi Pertanian, pp. 129136, 2018.

[3] R. Hartono, G. Sasono, S. Anggraeni, F. Suwanda and I. P, "Implementasi Algoritma Canny Edge Detection untuk Identifikasi Panjang dan Berat Ikan Koi Saat Bergerak," 2019.

[4] R. Islamadina, N. Pramita, F. Arnia, K. Munadi and M. Iqbal, "Pengukuran Badan Ikan Berupa Estimasi Panjang, Lebar,dan Tinggi Berdasarkan Visual Capture," Jurnal Nasional Teknik Elektro dan Teknologi Informasi (JNTETI), vol. 7, no. 1, pp. 57-63, 2018.

[5] G. Sanchez-Torres, A. Ceballos-Arroyo and S. Robles-Serano, "Automatic Measurement of Fish Weight and Size by Processing Underwater Hatchery Images," Engineering Letters, vol. 26, no. 4, 2018.

[6] D. Suhandy and U. Ahmad, "Pengembangan Algoritma Image processing untuk Menduga Kemasakan Buah Manggis Besar," Buletin keteknikan Pertanian, vol. 17, no. 2, pp. 29-38, 2003.

[7] H. Fitriyah, E. Setiawan and M. R. r. Masruri, "Applying Linear Regression to Estimate Weight of Non Axi-Symmetric fruit," jitecs (Journal of Information Technology, Engineering and Computer Science), vol. 5, no. 2, 2020 . 